$1-1-2012$

\title{
Capability of 2 Gait Measures for Detecting Response to Gait Training in Stroke Survivors: Gait Assessment and Intervention Tool and The Tinetti Gait Scale
}

\author{
Janice Zimbelman \\ Case Western Reserve University \\ Janis J. Daly \\ Case Western Reserve University \\ Kristen L. Roenigk \\ Louis Stokes Cleveland Department of Veterans Affairs Medical Center \\ Kristi Butler \\ Louis Stokes Cleveland Department of Veterans Affairs Medical Center \\ Richard Burdsall \\ Louis Stokes Cleveland Department of Veterans Affairs Medical Center \\ Follow this and additional works at: https://engagedscholarship.csuohio.edu/scimath_facpub

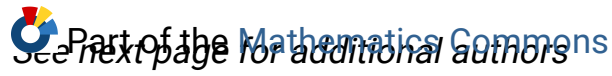 \\ How does access to this work benefit you? Let us know!
}

\section{Repository Citation}

Zimbelman, Janice; Daly, Janis J.; Roenigk, Kristen L.; Butler, Kristi; Burdsall, Richard; and Holcomb, John P. Jr., "Capability of 2 Gait Measures for Detecting Response to Gait Training in Stroke Survivors: Gait Assessment and Intervention Tool and The Tinetti Gait Scale" (2012). Mathematics Faculty Publications. 168.

https://engagedscholarship.csuohio.edu/scimath_facpub/168

This Article is brought to you for free and open access by the Mathematics and Statistics Department at EngagedScholarship@CSU. It has been accepted for inclusion in Mathematics Faculty Publications by an authorized administrator of EngagedScholarship@CSU. For more information, please contact library.es@csuohio.edu. 


\section{Authors}

Janice Zimbelman, Janis J. Daly, Kristen L. Roenigk, Kristi Butler, Richard Burdsall, and John P. Holcomb Jr.

This article is available at EngagedScholarship@CSU: https://engagedscholarship.csuohio.edu/scimath_facpub/168 


\title{
Capability of 2 Gait Measures for Detecting Response to Gait Training in Stroke Survivors: Gait Assessment and Intervention Tool and the Tinetti Gait Scale
}

\author{
Janice Zimbelman, PhD, Janis J. Daly, PhD, MS, Kristen L. Roenigk, BME, Kristi Butler, MSPT, \\ Richard Burdsall, PT, John P. Holcomb, PhD
}

Objective: To characterize the performance of 2 observational gait measures, the Tinetti Gait Scale (TGS) and the Gait Assessment and Intervention Tool (G.A.I.T.), in identifying improvement in gait in response to gait training.

Design: In secondary analysis from a larger study of multimodal gait training for stroke survivors, we measured gait at pre-, mid-, and posttreatment according to G.A.I.T. and TGS, assessing their capability to capture recovery of coordinated gait components.

Setting: Large medical center.

Participants: Cohort of stroke survivors $(\mathrm{N}=44)$ greater than 6 months after stroke.

Interventions: All subjects received 48 sessions of a multimodal gait-training protocol. Treatment consisted of 1.5 hours per session, 4 sessions per week for 12 weeks, receiving these 3 treatment aspects: (1) coordination exercise, (2) body weight-supported treadmill training, and (3) overground gait training, with $46 \%$ of subjects receiving functional electrical stimulation.

Main Outcome Measures: All subjects were evaluated with the G.A.I.T. and TGS before and after completing the 48session intervention. An additional evaluation was performed at midtreatment (after session 24).

Results: For the total subject sample, there were significant pre-/post-, pre-/mid-, and mid-/posttreatment gains for both the G.A.I.T. and the TGS. According to the G.A.I.T., 40 subjects (91\%) showed improved scores, 2 (4\%) no change, and $2(4 \%)$ a worsening score. According to the TGS, only 26 subjects (59\%) showed improved scores, 16 (36\%) no change, and 1 (2\%) a worsening score. For 1 treatment group of chronic stroke survivors, the TGS failed to identify a significant treatment response to gait training, whereas the G.A.I.T. measure was successful.

Conclusions: The G.A.I.T. is more sensitive than the TGS for individual patients and group treatment response in identifying recovery of volitional control of gait components in response to gait training.
$\mathbf{G}$ AIT ASSESSMENT IS an important component of the rehabilitation process. Instrumented gait assessment methods provide quantitative measures of gait kinematics, kinetics, and electromyographic activity of muscles. There is no doubt as to the superior advantage of instrumented gait assessment methods with respect to their quantitative nature and the possible degree of accuracy. However, despite the advantages, the literature contains multiple research studies that have used observational gait analysis methods, and in the clinical setting, observational gait analysis is routinely used. There are a number of reasons why instrumented gait analysis is not used in every research study nor routinely used in clinical practice. It is expensive, time intensive, and requires skilled analysis and interpretation, ${ }^{1-4}$ which can limit its practicality. The advantage of observational gait analysis, in general, has been that it is inexpensive and requires little or no technology. At the same time, the disadvantage of observational gait analysis versus instrumented gait analysis methods is that it has a lesser accuracy resolution. A criticism of observational gait analysis methods has been with regard to the relationship (or lack thereof) to the kinematic gait components they claim to measure. Studies $^{5-11}$ examining correlations between visual judgments and kinetic or kinematic measures are equivocal. Some have shown that because observational gait analysis depends on human visual judgment, it can be less reliable and less valid than instrumented gait measures, ${ }^{1,3}$ although others have reported high correlations between visual judgments and biomechanical measures. ${ }^{6,8-10}$ Despite this limitation, the fact is that observational gait analysis is widely used in clinical and research settings because of its ease of use and practicality.

\section{List of Abbreviations}

$\begin{array}{ll}\text { APTA } & \text { American Physical Therapy Association } \\ \text { BWSTT } & \text { body weight-supported treadmill training } \\ \text { CI } & \text { confidence interval } \\ \text { FES-IM } & \text { intramuscular functional electrical stimulation } \\ \text { G.A.I.T. } & \text { Gait Assessment and Intervention Tool } \\ \text { ICC } & \text { intraclass correlation coefficient } \\ \text { OG } & \text { overground gait training } \\ \text { TGS } & \text { Tinetti Gait Scale }\end{array}$


Since observational gait analysis is currently in use, it is important to use the optimal tool for the purpose at hand. A number of observational gait measures exist including the Wisconsin Gait Scale, ${ }^{12,13}$ Modified Gait Abnormality Rating Scale, ${ }^{9}$ Rivermead Visual Gait Index, ${ }^{14}$ Rancho Observational Gait Analysis, ${ }^{15}$ Bath Assessment of Walking Inventory, ${ }^{16}$ Tinetti Gait Scale (TGS), ${ }^{17}$ and Gait Assessment and Intervention Tool (G.A.I.T.). ${ }^{10}$ Both the Gait Abnormality Rating Scale and the G.A.I.T. have shown good $(r=.75$ and $r=.76$, respectively) correlation with selected kinematic measures. ${ }^{9}, 10$ Each of these observational measures has advantages and limitations, and each is capable of identifying a number of gait deviations; however, some may be more sensitive than others in assessing response to interventions for alleviating gait deviations.

For assessing response to interventions, a credible tool is one that correctly identifies clinically relevant deviations from normal gait and quantifies relevant changes in gait as a result of an intervention. ${ }^{3}$ Without reliable measurement performance, we forfeit 2 kinds of important capabilities: (1) the ability to credit efficacious rehabilitation methods, and (2) the ability to justify the financial support for providing effective gait training interventions. The StrokeEdge Taskforce of the American Physical Therapy Association (APTA) Neurology Section recently recommended the TGS for use in research gait assessment, ${ }^{18}$ as the preferred gait assessment tool. The G.A.I.T. is a more recently developed tool for gait assessment. ${ }^{10}$ It is more detailed, containing more items than the TGS, in order to assess specific coordinated gait movements ( 31 vs 8 items). The G.A.I.T. is more homogeneous than the TGS, in that it contains items that assess coordinated gait components; that is, given items contain both the spatial and temporal aspects of coordination $^{19}$ (eg, amount of knee flexion [spatial] at midswing [temporal]), and it captures the amount of deviation from normal gait coordination. In contrast, the TGS includes given items that assess only the temporal aspect of gait description (eg, step length) or compensatory strategies such as gait asymmetry or step discontinuity. The brevity and heterogeneity of the TGS may limit its ability to detect some changes in gait in response to gait training. Despite this potential limitation, the TGS is widely used in the literature ${ }^{20}$ and has been recommended by the APTA as the scale to use in research gait assessment. ${ }^{18}$ Therefore, the purpose of the current work was to use secondary analysis to assess the performance of 2 observational gait measures, the TGS and the G.A.I.T., to identify changes in gait in response to gait training.

\section{METHODS}

\section{Participants}

A cohort of 44 subjects were evaluated, who were enrolled in a gait-training trial described elsewhere. ${ }^{21}$ Inclusion criteria were as follows: greater than 6 months after a single stroke; inability to flex the hip, knee, and ankle normally in the sagittal plane, or hyperflexion or hyperextension of the knee during stance; and passive joint range of motion of the hip, knee, and ankle equal to the normal excursion needed for walking. Exclusion criteria included an inability to follow 2-level commands, peripheral neuropathy, and debilitating illness (eg, cancer). The study was approved by the medical center institutional review board, and a written informed consent process was conducted.

\section{Intervention}

All subjects received 48 sessions of gait training using a multimodal protocol as part of a clinical trial comparing intra- muscular functional electrical stimulation (FES-IM) and no FES (46\% received FES). ${ }^{21}$ Treatment consisted of 1.5 hours per session, 4 sessions per week for 12 weeks, and included these 3 treatment aspects: (1) coordination exercise, (2) body weight-supported treadmill training (BWSTT), and (3) overground gait training (OG), with $46 \%$ of subjects receiving FES-IM. Exercise included practice of the coordinated joint movements that underlie gait components. ${ }^{22}$ BWSTT was conducted using the Biodex $500,{ }^{\text {a }}$ beginning with $30 \%$ body weight support and decreasing to $0 \%$, according to the subject's ability to maintain normal, neutral alignment of the torso and stance limb. Walking training speed was increased up to $.894 \mathrm{~m} / \mathrm{s}$, as tolerated. OG included training in the following: torso, pelvic, hip, knee, and ankle position control during loading and weight bearing; swing hip, knee, and ankle flexion; and terminal swing knee extension/ankle dorsiflexion. Home exercises were coordination exercises performed for $1 \mathrm{~h} / \mathrm{d}$. FES-IM was used to treat pelvic stability during stance phase, knee extension at loading, ankle dorsiflexion during swing, knee flexion at toeoff, and knee flexion during swing. ${ }^{23-25}$

\section{Measures}

The G.A.I.T. contains 31 items of coordinated gait components, divided into 3 sections: Section A contains 4 items for upper extremity and trunk movement control that occur during both stance and swing phase; Section B contains 14 items for the trunk and lower extremity that are unique to stance phase; and Section C contains 13 items for the trunk and lower extremity that are unique to swing phase. ${ }^{10}$ Deviations from normal are listed as scoring choices within each item. Scoring for each item ranges from 0 (normal) up to 3 , with deviations from normal defined and scored as 1,2 , or 3 points. The G.A.I.T. ranges from 0 (normal) to 62 points (greatest extent of gait deviations). The G.A.I.T. has good intrarater reliability ${ }^{26}$ (intraclass correlation coefficient $[\mathrm{ICC}]=.98 ; P=.0001 ; 95 \%$ confidence interval [CI], .95-.99) and good interrater reliability $\left(\mathrm{ICC}=.83 ; P=.007 ; 95 \%\right.$ CI, .32-.96) ${ }^{10}$ Items on the G.A.I.T. demonstrated significant correlations with motion capture data for knee flexion at toe-off $(r=.65, P=.001)$ and peak swing knee flexion $(r=.76, P=.0001) .{ }^{10}$ The G.A.I.T. was developed by 8 experienced physical therapist clinicians ${ }^{10}$ as a detailed observational measure of coordinated gait components to quantify response to gait training interventions. ${ }^{10}$ With a scoring time of 20 minutes, the G.A.I.T. has been tested and can be used in a relatively low tech environment with a video camera to record the gait pattern and a video player with "playback," "stop-frame" capability for scoring some items.

The TGS contains 8 items assessing the following: deficits in coordinated gait components ( 2 items), compensatory strategies (5 items), and temporal aspects of gait (1 item). ${ }^{17}$ Six items are scored as 0 (deviation) or 1 (normal) point; 2 items are scored as 0,1 , (deviations), or 2 (normal) points. The TGS ranges from 0 (most deviations) to 12 points (normal). The TGS has good interrater reliability $(r=.80-.89)$, moderate to good test-retest reliability $(r=.72-.77),{ }^{27}$ and good intrarater reliability $(r=.95){ }^{28}$ The TGS was originally developed to identify abnormal gait ${ }^{17}$ and takes 5 minutes to score. We chose to compare the G.A.I.T. with the TGS because the TGS is used widely in research studies ${ }^{20}$ and has been recommended by the APTA as the observational measure of choice for research gait assessment. ${ }^{18}$

\section{Testing}

Twelve subjects ambulated without an assistive device on entering the study; 31 subjects ambulated with an assistive 
Table 1: Initial Ambulatory Status Used for Pre-, Mid-, and Posttreatment Testing

\begin{tabular}{lc}
\hline \multicolumn{1}{c}{ Assistive Device } & No. of Subjects \\
\hline No assistive device & 12 \\
Standard cane & 15 \\
Small-based cane & 4 \\
Large-based cane & 8 \\
Large-based cane and AFO & 3 \\
Parallel bars/hemi-walker & $1 *$
\end{tabular}

Abbreviation: AFO, ankle-foot orthosis

* One subject used parallel bars at pretreatment, of necessity, and a hemi-walker at posttesting.

device (table 1). Each given subject was consistently tested at pre-/mid-/posttreatment tests (and without FES-IM), using their own consistent assistive device at each test session. The examiners in this study were physical therapists with more than 10 years of experience in clinical practice and gait assessment, and more than 3 years of experience in using the G.A.I.T. and TGS measures. For a given subject, the examiner was consistent for pre-/mid-/posttreatment measures, and the same examiner scored both the G.A.I.T. and the TGS measures. The examiners were blinded as to the purpose of the study.

\section{Data Analysis}

Overall change scores (pretreatment minus posttreatment; pretreatment minus midtreatment; midtreatment minus posttreatment) were calculated for the G.A.I.T. and the TGS. A change score was also calculated for each item for each measure. We generated descriptive statistics to examine the distribution of total and item change scores for each measure. The Wilcoxon signed-rank test was used for the following comparisons: pre-/post-, pre-/mid-, and mid-/posttreatment scores. The Sidak step-down procedure was used to correct for multiple comparisons. Correlation between gait coordination and gait speed was calculated using measured gait speed $(\mathrm{m} / \mathrm{s})$ and the G.A.I.T., using the Spearman model; this was repeated for the TGS and measured gait speed.

\section{RESULTS}

\section{Total Score Analysis}

The G.A.I.T. detected a significant pre-/posttreatment gain $(P=.0001$; pre-/posttreatment median and interquartile range were 33.75 [9.75] and 25.5 [8.625], respectively); G.A.I.T. gain scores ranged from -1 (worsening) to +17 (improvement) points. The TGS also detected a significant pre-/posttreatment gain $(P=.0001$; pre-/posttreatment median and interquartile range were 6.0 [3.0] and 8.0 [3.0], respectively); TGS gain scores ranged from -3 (worsening) to +6 (improvement) points. Descriptive statistics for the individual subject change scores for each measure revealed that $40(91 \%)$ of the 44 subjects showed improved scores according to the G.A.I.T., 2 (4\%) showed no change, and $2(4 \%)$ showed a worsened score. According to the TGS, $26(59 \%)$ of the 44 subjects showed improved scores, $16(36 \%)$ showed no change, and $1(2 \%)$ showed a worsened score (fig 1). Figure 1 shows that there was a difference for the TGS versus the G.A.I.T. regarding the number of subjects who had no recovery of gait component performance. The G.A.I.T. measure identified that only $11.4 \%$ of subjects had none to minimal gains ( $0-1$ point), whereas the TGS suggested that $56.8 \%$ of subjects had none to minimal gains.

We conducted a secondary exploratory descriptive analysis to equilibrate the difference in the 2 scales, specifically the G.A.I.T., which has a total score of 62 points, and the TGS, which has a total score of 12 points (5:1 ratio). We can note that a 1-point gain on the TGS could be considered equivalent to a 5-point gain on the G.A.I.T. Using this algorithm, we found that $28(63.6 \%)$ of the 44 subjects demonstrated greater than a 5-point pre-/posttreatment G.A.I.T. gain, which was greater than the $17(38.6 \%)$ subjects demonstrating greater than a 1-point pre-/posttreatment TGS gain.

The G.A.I.T. detected a significant pre-/midtreatment gain $(P=.001$; pre-/midtreatment median and interquartile range were 33.75 [9.75] and 28.5 [9.0], respectively) and a significant mid-/posttreatment gain $(P=.0001$; mid-/posttreatment median and interquartile range, 28.5 [9.0] and 25.5 [8.625], respectively). The TGS also detected a significant pre-/midtreatment gain $(P=.0001$; pre-/midtreatment median and interquartile
Fig 1. Individual subject change scores for the G.A.I.T. and the TGS. Each circle represents a single subject; positive numbers indicate gain, negative numbers indicate loss.

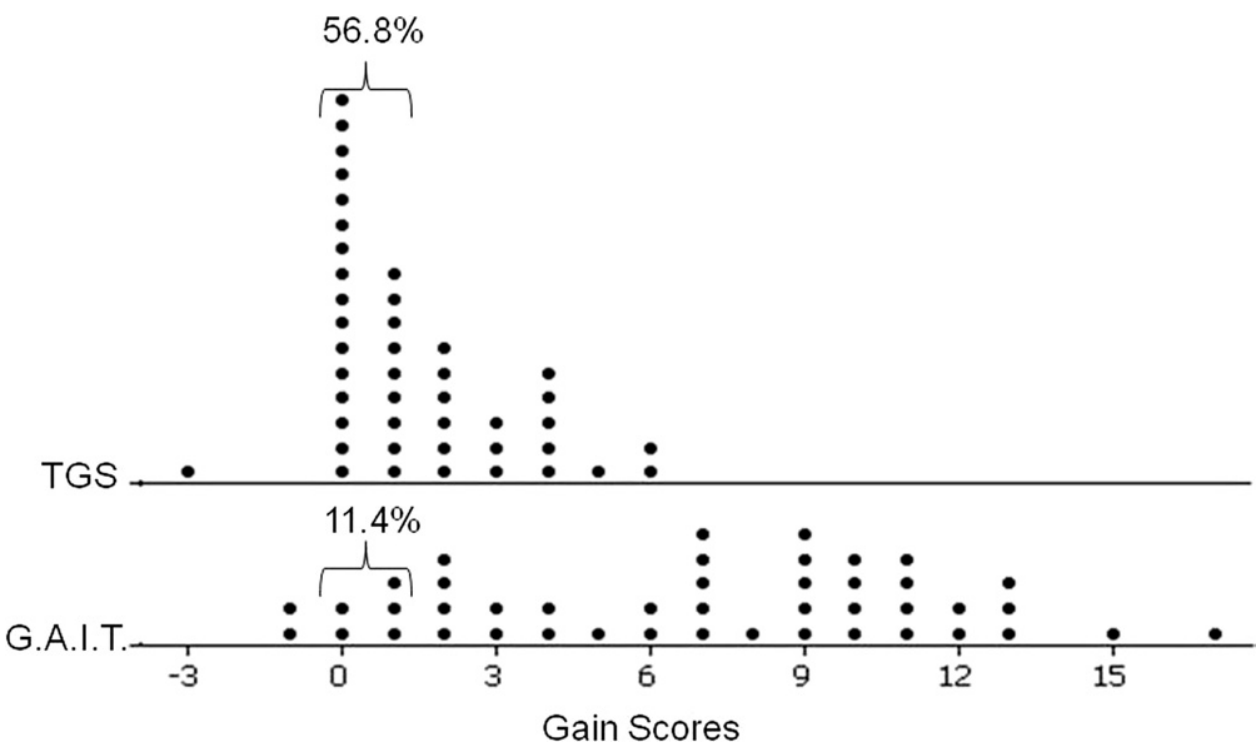


Table 2: Items Common to Both Measures

\begin{tabular}{|c|c|c|c|}
\hline \multicolumn{2}{|c|}{ G.A.I.T. Items Comparable With TGS Items } & \multicolumn{2}{|c|}{ TGS Items Comparable With G.A.I.T. Items } \\
\hline Item No. & Item Description & Item No. & Item Description \\
\hline 24 & Hip flexion (swing phase) & 2 & Step length and height-swing foot \\
\hline 27 & Knee-midswing & 2 & Step length and height-swing foot \\
\hline 29 & Ankle movement (swing phase) & 2 & Step length and height-swing foot \\
\hline 5 & Trunk posture (stance phase; sagittal plane) & 7 & Trunk sway \\
\hline 6 & Trunk posture (stance phase; coronal plane) & 7 & Trunk sway \\
\hline 19 & Trunk posture (swing phase; sagittal plane) & 7 & Trunk sway \\
\hline 20 & Trunk posture (swing phase; coronal plane) & 7 & Trunk sway \\
\hline
\end{tabular}

range were 6.0 [3.0] and 7.0 [2.0], respectively) and a significant mid-/posttreatment gain $(P=.006$; mid-/posttreatment median and interquartile range, 7.0 [2.0] and 8.0 [3.0], respectively). Both the G.A.I.T. and the TGS were correlated with gait speed $([r=.735, P=.0001]$ and $[r=.739, P=.0001]$, respectively).

For gait speed, there was a statistically significant pre-/ midtreatment gain $(P=.0001$; pre-/midtreatment mean $\pm \mathrm{SD}$, $.396 \pm .245 \mathrm{~m} / \mathrm{s}$ and $.477 \pm .284 \mathrm{~m} / \mathrm{s}$, respectively). But the gain in gait speed from pre-/midtreatment was $.08 \mathrm{~m} / \mathrm{s}$, which is below the current standard of $.16 \mathrm{~m} / \mathrm{s}$ for a minimally clinically significant change. $^{29}$ There was a significant mid-/posttreatment gain $(P=.001)$; mid-/posttreatment mean $\pm \mathrm{SD}$ values were $.477 \pm .284 \mathrm{~m} / \mathrm{s}$ and $.536 \pm .329 \mathrm{~m} / \mathrm{s}$, respectively. However, the gain in gait speed from mid-/posttreatment was $.06 \mathrm{~m} / \mathrm{s}$, which is below the current standard of $.16 \mathrm{~m} / \mathrm{s}$ for a minimally clinically significant change. ${ }^{29}$ The overall pre-/ posttreatment gait speed gain was statistically significant $(P=.0001)$, with mean $\pm \mathrm{SD}$ values of $.396 \pm .245 \mathrm{~m} / \mathrm{s}$ and $.536 \pm .329 \mathrm{~m} / \mathrm{s}$, respectively. However, the gain in gait speed from pre-/posttreatment was $.14 \mathrm{~m} / \mathrm{s}$, which is slightly below the current standard of $.16 \mathrm{~m} / \mathrm{s}$ for a minimally clinically significant change. ${ }^{29}$

\section{Individual Item Scores}

The item content for both measures is listed in table 2, drawing potential commonalities for the G.A.I.T. and the TGS items. Although not a one-to-one commonality, the TGS item "step length and height" may be affected by the extent of movement excursion for swing phase hip flexion and/or knee flexion and/or ankle dorsiflexion; these latter 3 components are measured as separate items in the G.A.I.T., but the effects of these 3 items are considered as only a single item in the TGS. The G.A.I.T. measures trunk posture during both swing and stance phases, and within 2 different planes (sagittal and coronal), resulting in 4 individual items; the TGS measures trunk sway as a single item. Table 3 lists the items that are unique to either of the measures.

Individual items of each measure were able to distinguish gains. Table 4 lists the items for each measure that captured a gain score of 1 point or more. Twenty-eight (90\%) of the 31

Table 3: Items Unique to Each Measure

\begin{tabular}{|c|c|c|c|}
\hline \multicolumn{2}{|r|}{ G.A.I.T. Items Not in TGS } & \multicolumn{2}{|c|}{ TGS Items Not in G.A.I.T. } \\
\hline Item No. & Item Description & Item No. & Item Description \\
\hline 1 & Shoulder position (stance and swing) & 1 & Initiation of gait \\
\hline 2 & Elbow flexion (stance and swing) & 4 & Step symmetry \\
\hline 3 & Arm swing (stance and swing) & 5 & Step continuity \\
\hline 4 & Trunk alignment (static) & 6 & Path \\
\hline 7 & Weight shift (stance phase) & 8 & Step width \\
\hline 8 & Pelvic position (stance phase) & & \\
\hline 9 & Hip extension (stance phase) & & \\
\hline 10 & Hip rotation (stance phase) & & \\
\hline 11 & Knee-initial contact phase & & \\
\hline 12 & Knee-loading response phase & & \\
\hline 13 & Knee-midstance phase & & \\
\hline 14 & Knee terminal/preswing phase & & \\
\hline 15 & Ankle movement (stance phase) & & \\
\hline 16 & Ankle inversion (stance phase) & & \\
\hline 17 & Plantar flexion during terminal/preswing & & \\
\hline 18 & Toe position (stance phase) & & \\
\hline 21 & Pelvic position (swing phase; coronal plane) & & \\
\hline 22 & Pelvic position (swing phase; sagittal plane) & & \\
\hline 23 & Pelvic rotation as limb swings forward & & \\
\hline 25 & Hip rotation (swing phase) & & \\
\hline 26 & Knee-initial swing & & \\
\hline 30 & Ankle inversion (swing phase) & & \\
\hline 31 & Toe position (swing phase) & & \\
\hline
\end{tabular}


Table 4: Items in Which Subjects Exhibited Gain Scores on the G.A.I.T. or TGS

\begin{tabular}{|c|c|c|c|c|c|c|c|}
\hline \multicolumn{4}{|c|}{ G.A.I.T. Items } & \multicolumn{4}{|c|}{ TGS Items } \\
\hline $\begin{array}{l}\text { Item } \\
\text { No. }\end{array}$ & Item Description & $\begin{array}{c}\text { No. of } \\
\text { Subjects }\end{array}$ & $\begin{array}{c}\% \text { of } \\
\text { Subjects }\end{array}$ & $\begin{array}{l}\text { Item } \\
\text { No. }\end{array}$ & Item Description & $\begin{array}{c}\text { No. of } \\
\text { Subjects }\end{array}$ & $\begin{array}{c}\% \text { of } \\
\text { Subjects }\end{array}$ \\
\hline 1 & Shoulder position & 2 & $4 \%$ & 1 & Gait initiation & 5 & $11 \%$ \\
\hline 2 & Elbow flexion & 6 & $13 \%$ & 2 & Step length and height-right swing foot & 17 & $39 \%$ \\
\hline 4 & Trunk alignment (static) & 18 & $41 \%$ & 3 & Step length and height-left swing foot & 13 & $30 \%$ \\
\hline 5 & Trunk posture (stance phase; sagittal plane) & 15 & $34 \%$ & 4 & Step symmetry & 11 & $25 \%$ \\
\hline 6 & Trunk posture (stance phase; coronal plane) & 12 & $27 \%$ & 5 & Step continuity & 10 & $23 \%$ \\
\hline 7 & Weight shift (stance phase) & 16 & $36 \%$ & 6 & Path (deviation from or uses walking aid) & 7 & $16 \%$ \\
\hline 8 & Pelvic position (stance phase; coronal plane) & 4 & $9 \%$ & 7 & Trunk sway & 7 & $16 \%$ \\
\hline 9 & Hip extension (stance phase) & 9 & $20 \%$ & 8 & Step width & 8 & $18 \%$ \\
\hline 10 & Hip rotation (stance phase) & 8 & $18 \%$ & & & & \\
\hline 11 & Knee-initial contact phase & 15 & $34 \%$ & & & & \\
\hline 12 & Knee-loading response phase & 11 & $25 \%$ & & & & \\
\hline 13 & Knee-midstance phase & 18 & $41 \%$ & & & & \\
\hline 14 & Knee terminal/preswing phase & 18 & $41 \%$ & & & & \\
\hline 15 & Ankle movement (stance phase) & 10 & $23 \%$ & & & & \\
\hline 16 & Ankle inversion (stance phase) & 10 & $23 \%$ & & & & \\
\hline 17 & Plantar flexion terminal stance & 9 & $20 \%$ & & & & \\
\hline 19 & Trunk posture (swing phase; sagittal plane) & 10 & $23 \%$ & & & & \\
\hline 20 & Trunk posture (swing phase; coronal plane) & 12 & $27 \%$ & & & & \\
\hline 21 & Pelvic position (swing phase; coronal plane) & 14 & $32 \%$ & & & & \\
\hline 22 & Pelvic position (swing phase; sagittal plane) & 4 & $9 \%$ & & & & \\
\hline 23 & Pelvic rotation as limb swings forward & 12 & $27 \%$ & & & & \\
\hline 24 & Hip flexion (swing phase) & 12 & $27 \%$ & & & & \\
\hline 25 & Hip rotation (swing phase) & 13 & $30 \%$ & & & & \\
\hline 26 & Knee-initial swing & 13 & $30 \%$ & & & & \\
\hline 27 & Knee-midswing & 12 & $27 \%$ & & & & \\
\hline 28 & Knee-terminal swing & 4 & $9 \%$ & & & & \\
\hline 29 & Ankle movement (swing phase) & 11 & $25 \%$ & & & & \\
\hline 30 & Ankle inversion (swing phase) & 16 & $36 \%$ & & & & \\
\hline
\end{tabular}

G.A.I.T. items, and all 8 TGS items were able to capture gains in at least 1 subject.

\section{Treatment Effect for Each FES-IM and No FES Group}

We examined the capability of the G.A.I.T. and TGS to detect a significant treatment effect for those who did not receive FES-IM (No FES, $n=24$ ) and those who did receive FES-IM $(n=20)$. Results of this analysis are in table 5. Both measures were able to detect significant change in pre-/posttreatment scores in both the FES-IM and No FES groups. In addition, both measures detected significant change in pre-/ midtreatment scores for both groups; however, only the G.A.I.T. detected significant continued change from mid- to posttreatment.

\section{DISCUSSION}

Results showed that both measures were able to detect significant pre-/posttreatment gains in response to gait retraining in a group of 44 subjects with stroke. Both measures were able to identify change in some individual subjects as shown in figure 1. However, the G.A.I.T. identified improvement in a much larger percentage of the subjects compared with the TGS (91\% vs 59\%). In fact, only 2 subjects showed no change in their total G.A.I.T. score; in contrast, 16 subjects showed no change according to the TGS. Justification of treatment has become critical in terms of obtaining insurance coverage for rehabilitation; when there is no credible progress measured, treatment is not continued. Notably, figure 1 shows that ac-

Table 5: Capability of TGS and G.A.I.T. Measures to Detect Significant Improvement From Pre- to Midtreatment and From Mid- to Posttreatment for Each of Two Treatment Groups

\begin{tabular}{|c|c|c|c|c|c|c|c|c|c|c|c|c|}
\hline & \multicolumn{4}{|c|}{ Pre- to Midtreatment Comparison } & \multicolumn{4}{|c|}{ Mid- to Posttreatment Comparison } & \multicolumn{4}{|c|}{ Pre- to Posttreatment Comparison } \\
\hline & $\begin{array}{l}\text { Pre Median } \\
\qquad(I Q R)\end{array}$ & $\begin{array}{l}\text { Mid Median } \\
\quad(I Q R)\end{array}$ & $P$ & $\begin{array}{c}\text { Corrected } \\
P\end{array}$ & $\begin{array}{l}\text { Mid Median } \\
\quad(I Q R)\end{array}$ & $\begin{array}{l}\text { Post Median } \\
\text { (IQR) }\end{array}$ & $P$ & $\begin{array}{c}\text { Corrected } \\
P\end{array}$ & $\begin{array}{l}\text { Pre Median } \\
\quad(I Q R)\end{array}$ & $\begin{array}{l}\text { Post Median } \\
\text { (IQR) }\end{array}$ & $P$ & $\begin{array}{c}\text { Corrected } \\
P\end{array}$ \\
\hline \multicolumn{13}{|l|}{ G.A.I.T. } \\
\hline FES & $33.75(9.75)$ & $28.00(8.75)$ & 0.003 & 0.009 & $28.00(8.75)$ & $25.00(7.75)$ & 0.001 & 0.004 & $33.75(9.75)$ & $25.00(7.75)$ & 0.0001 & 0.0004 \\
\hline No FES & $33.50(9.75)$ & $31.50(7.37)$ & 0.036 & 0.036 & $31.50(7.38)$ & $27.50(9.00)$ & 0.004 & 0.012 & $33.50(9.75)$ & $27.50(9.00)$ & 0.0001 & 0.0004 \\
\hline \multicolumn{13}{|l|}{ TGS } \\
\hline FES & $6.0(2.75)$ & $7.0(2.5)$ & 0.002 & 0.008 & $7.0(2.5)$ & $8.0(2.75)$ & 0.026 & $0.051 *$ & $6.0(2.75)$ & $8.0(2.75)$ & 0.002 & 0.002 \\
\hline No FES & $5.0(3.00)$ & $6.0(3.0)$ & 0.003 & 0.009 & $6.0(3.0)$ & $6.0(3.00)$ & 0.131 & $0.131 *$ & $5.0(3.00)$ & $6.0(3.00)$ & 0.001 & 0.004 \\
\hline
\end{tabular}

Abbreviation: IQR, interquartile range.

* No significant difference detected. 
cording to the TGS, treatment would be terminated for $56.8 \%$ (25) of the subjects (0- to 1-point change in response to treatment), whereas treatment would be terminated for only $11.4 \%$ (5) of the individuals according to the G.A.I.T. measure. In that case, 20 individuals would be deprived of treatment that would have had a positive effect on their coordinated gait. These results indicate that the G.A.I.T. was more sensitive than the TGS in discriminating actual change in coordination of walking ability.

We further examined the capability of the G.A.I.T. and TGS to detect change for each of 2 treatment groups (FES-IM and No FES). Table 5 shows that the TGS detected significant change only during the first 24 sessions, but not for the subsequent 24 sessions from mid- to posttreatment. In contrast, the G.A.I.T. detected significant change not only during the first 24 sessions, but also during the latter 24 sessions. This finding illustrates that if only the TGS were used to examine treatment efficacy, it would erroneously be concluded that subjects had plateaued by the end of the first 24 sessions and did not have any further recovery during the latter 24 sessions. If guidelines were based on that information, stroke survivors would be deprived of efficacious gait training. Moreover, the G.A.I.T. results not only indicate that recovery continued throughout the latter 24 sessions, but also point to the possibility that even additional gait training might be beneficial and lead to further recovery. According to the G.A.I.T. measure, since there was no plateau between mid- and posttreatment, justification for follow-up research questions is revealed as follows: (1) how much more gait training would be beneficial? and (2) how much more recovery could be achieved?

There are several reasons why the G.A.I.T. may be more sensitive than the TGS. First, the G.A.I.T. is more homogeneous than the TGS. Item content for the TGS includes not only coordinated gait components (step length/height), but also compensatory strategies such as abnormal step width, gait asymmetry, and step discontinuity (see table 3 ). Subjects may have improved on some coordinated gait components measured by the G.A.I.T., but perhaps not all the gait components encompassed by the more global compensatory strategies assessed by the TGS. For example, subjects improved weight shift and pelvic position as measured with the G.A.I.T., but still had some balance deficit that required the compensatory strategy of an abnormally wide step width measured by the TGS.

Second, the G.A.I.T. is more detailed, containing more items and possessing a higher total score ( 31 items, 62 points) than the TGS ( 8 items, 12 points). Table 3 shows that the G.A.I.T. possesses a greater number of unique items versus the TGS. Hip, knee, and ankle excursion during the swing phase of gait each have the ability to affect step length and height. These individual joint excursions are measured and scored separately as individual items in the G.A.I.T., whereas the effects of these 3 items are considered together in only 1 global item (step length and height) in the TGS. In other words, step length and height are assessed by the TGS, but the specific coordinated means that were used to achieve normal step length and height are not measured. Without the identification of the specific gait dyscoordination, and recovery thereof, the clinician and the researcher are not provided with clear guidance for gait coordination training and with clear research evidence, respectively.

A second example of the advantage of a more detailed measure is that the G.A.I.T. has 14 items to assess trunk, pelvic, hip, knee, and ankle coordination gait components during the stance phase of gait, and 13 items for coordination gait components during the swing phase of gait. The TGS has 1 item assessing stance phase of gait (step width) and 2 items assessing swing phase: right step length/height and left step length/height. As shown in table 4, at least 10 subjects demonstrated improvement on 9 stance and 10 swing phase gait component movements according to the G.A.I.T. measure; however, the 1 relevant swing-phase coordination item in the TGS was not constructed in a manner that was sufficient to capture those gains. For example, the improved knee flexion in swing phase that was captured by the G.A.I.T. measure may not have been sufficient for detection by the TGS, which required recovery of whole-limb performance to detect change in the more gross-movement TGS item.

A third reason why the G.A.I.T. measure is more sensitive may be that the G.A.I.T. is capable of measuring incremental changes within given gait components. Twenty-four of the G.A.I.T. items require a determination of the degree of the deficit. The G.A.I.T. was designed in this way to capture an incremental response to treatment within the domain of the given gait component. For example, the item "knee-midswing" is rated as $0\left(60^{\circ}\right.$, normal $), 1\left(45^{\circ}-55^{\circ}\right), 2\left(25^{\circ}-45^{\circ}\right)$, or 3 $\left(0^{\circ}-25^{\circ}\right)$ depending on the amount of knee flexion performed. During treatment, a patient may improve gradually, over time, in the amount of knee flexion executed at midswing. The capability of a gait measure to show incremental change over time allows the clinician to document that the patient has not yet plateaued and deserves more treatment for the measured rehabilitation potential. Accurately identified gains illustrate for the researcher that a new protocol is efficacious and/or that full recovery may not have yet been reached and study is warranted of additional treatment duration. The incremental improved knee flexion would be reflected in a change score in the G.A.I.T. However, for the TGS, this incremental improvement in knee flexion cannot be captured, and it would appear that the patient had not responded to intervention. In that case, promising treatment would be denied to a patient who actually was exhibiting progress (but unmeasured) and potential for further recovery. In the realm of research, a potentially efficacious treatment might be inaccurately classified as not beneficial, if incremental gains are not identified.

Gait measures should not only determine whether a deficit exists, but also assist in clinical decision-making, guiding treatment decisions. The TGS was designed as a clinical measure to detect obvious problems with gait (ie, identify abnormal gait). ${ }^{17}$ Its advantage is that it is simple to use, only takes a few minutes to administer, and does identify obvious problems with gait. However, because it is not comprehensive, it is not able to guide treatment decisions aimed at recovery of gait coordination and normal walking ability. A measure such as the G.A.I.T. that is comprehensive is able to guide treatment by assisting the therapist with identifying deficits in specific gait components. For example, the TGS will identify a deficit in the ability to bring the swing foot past the stance foot (abnormal gait characteristic). However, the G.A.I.T. provides the therapist with an assessment tool and a score regarding whether this inability is due to insufficient hip, knee, or ankle dorsiflexion during swing or insufficient hip or knee extension during stance, or abnormal weight shift during stance. Any of these deficits lead to the 1 deficit measured by the TGS single item (bringing the swing foot past the stance foot). The G.A.I.T. provides a means to analyze several sources of the gait deficits, providing a guide to focus on specific training options to improve gait performance.

Gait speed is widely recommended as an outcome measure in the poststroke gait literature, and some would argue that it is the criterion standard measurement for "gait function."30-32 According to gait speed $(\mathrm{m} / \mathrm{s})$ results in the current study, there was a statistically significant gain for the paired comparisons 
between each of the data acquisition time points (pre-/mid-/ posttreatment). Some have reported that a gait speed gain of 16 $\mathrm{m} / \mathrm{s}$ is a minimal clinically important difference that can be used by clinicians to develop goals and interpret progress in patients after stroke. ${ }^{29}$ If that criterion were exclusively used in the current study, we would have to conclude that none of the comparisons (pre-/posttreatment; pre-/midtreatment; and mid-/ posttreatment) reached a gain in gait speed of $.16 \mathrm{~m} / \mathrm{s}$, and so were not clinically significant. Gait speed is related in a number of ways to gait coordination. Gait coordination can be considered a higher order property of the human system, controlled by the central nervous system. ${ }^{19}$ The relationship between gait coordination and gait speed is complex. We do know that normally coordinated gait results in a self-selected gait speed averaging $1.39 \mathrm{~m} / \mathrm{s},{ }^{33,34}$ which is the optimal walking speed in terms of energy expenditure. ${ }^{35} \mathrm{We}$ also know that impaired gait coordination can lead to abnormally reduced gait speed as well as poor walking endurance after stroke. Some stroke survivors can adopt compensatory strategies such as hip hiking and circumducting that can be observed in a "stiff-legged" gait. These compensatory strategies may enable a faster walking speed, ${ }^{36}$ but at the same time, they are less efficient in terms of energy cost versus normal gait coordination ${ }^{37}$ and can be less desirable for a number of reasons ${ }^{19}$ such as poor safety and propensity to fall. $^{25}$ The complex relationship between gait coordination and gait speed justifies the use of both types of measures in analyzing gait deficits and response to gait training.

\section{Study Limitations}

There are a number of available tools for characterizing and measuring gait coordination. It was beyond the scope of the current study to assess them all. This study was focused to study 2 observational gait measures. We selected the G.A.I.T. because it is a detailed and homogeneous measure of coordinated gait components that informs the therapist of gait deviations and provides a mechanism to evaluate progress and establish treatment goals for gait training. We selected the TGS because it is widely used in the literature and was recommended by the APTA StrokeEdge Taskforce as the observational gait measure of choice for research. The study sample was limited to 44 stroke survivors who were 6 months poststroke. The gait-training protocol that produced the pre-/posttreatment scores was confined to the combination of exercise, BWSTT, and OG, with or without FES-IM, depending on assignment. The types of measures were limited to 2 observational gait coordination measures and gait speed.

\section{CONCLUSIONS}

In the current health care environment, it is critical to measure response to interventions in a manner that is accurate, comprehensive, and sensitive to incremental change. Without this capability, we forfeit the ability to credit efficacious rehabilitation interventions and to justify the financial support of providing effective gait-training methods. The current study demonstrated that the G.A.I.T. is more sensitive for individual stroke survivors than the TGS in identifying improvement in volitional control of gait component coordination in response to gait training. We found that the TGS missed the accurate identification of recovery of gait coordination in a large percentage of stroke survivors. The G.A.I.T. exhibited better capability than the TGS in identifying a significant response to treatment for a group of chronic stroke survivors.

\section{References}

1. Coutts F. Gait analysis in the therapeutic environment. Man Ther 1999;4:2-10
2. Davis RB. Reflections on clinical gait analysis. J Electromyogr Kinesiol 1997;7:251-7.

3. Toro B, Nester C, Farren P. A review of observational gait assessment in clinical practice. Physiother Theory Pract 2003;19: 137-49.

4. Chapin KB. A focus on clinical gait analysis. Rehab Manag 2010;23:10-2.

5. Harrison EL, Duenkel N, Dunlop R, Russell G. Evaluation of single-leg standing following anterior cruciate ligament surgery and rehabilitation. Phys Ther 1994;74:245-52.

6. Haupstein T, Goldie P. Visual judgements of steadiness in onelegged stance: reliability and validity. Physiother Res Int 2000;5: 141-56.

7. Miyazaki S, Kubota T. Quantification of gait abnormalities on the basis of continuous foot-force measurement: correlation between quantitative indices and visual rating. Med Biol Eng Comput 1984;22:70-6.

8. McGinley JL, Morris ME, Greenwood KM, Goldie PA, Olney SJ. Accuracy of clinical observations of push-off during gait after stroke. Arch Phys Med Rehabil 2006;87:779-85.

9. Vanswearingen JM, Paschal KA, Bonino P, Yang JF. The modified Gait Abnormality Rating Scale for recognizing the risk of recurrent falls in community-dwelling elderly adults. Phys Ther 1996;76:994-1002.

10. Daly JJ, Nethery J, McCabe JP, et al. Development and testing of the Gait Assessment and Intervention Tool (G.A.I.T.): a measure of coordinated gait components. J Neurosci Methods 2009;178: 334-9.

11. Patla AE, Clouse SD. Visual assessment of human gait: reliability and validity. Rehabil Res 1988;(October):87-96.

12. Rodriquez AA, Black PO, Kile KA, et al. Gait training efficacy using a home-based practice model in chronic hemiplegia. Arch Phys Med Rehabil 1996;77:801-5.

13. Turani N, Kemiksizoglu A, Karatas M, Ozker R. Assessment of hemiplegic gait using the Wisconsin Gait Scale. Scand J Caring Sci 2004;18:103-8.

14. Lord SE, Halligan PW, Wade DT. Visual gait analysis: the development of a clinical assessment and scale. Clin Rehabil 1998; 12:107-19.

15. Perry J. Gait analysis: normal and pathological function. Thorofare: Slack; 1992.

16. Clarke JE, Eccleston C. Assessing the quality of walking in adults with chronic pain: the development and preliminary psychometric evaluation of the Bath Assessment of Walking Inventory. Eur J Pain 2009;13:305-11.

17. Tinetti ME. Performance-oriented assessment of mobility problems in elderly patients. J Am Geriatr Soc 1986;34:119-26.

18. Zipp GP, Sullivan JE, Rose DK, et al. Neurology section outcome measures recommendations: stroke. Available at: http:// www.neuropt.org/go/healthcare-professionals/neurology-sectionoutcome-measures-recommendations/stroke. Accessed February 16, 2011.

19. Krasovsky T, Levin MF. Review: toward a better understanding of coordination in healthy and poststroke gait. Neurorehabil Neural Repair 2010;24:213-24.

20. Kopke S, Meyer G. The Tinetti test: Babylon in geriatric assessment. Z Gerontol Geriatr 2006;39:288-91.

21. Daly JJ, Zimbelman J, Roenigk KL, et al. Recovery of coordinated gait: randomized controlled stroke trial of functional electrical stimulation (FES) versus no FES, with weight-supported treadmill and over-ground training. Neurorehabil Neural Repair 2011;25: 588-96.

22. Ryerson S, Levit K. Functional movement reeducation: a contemporary model for stroke rehabilitation. New York: Churchill Livingstone; 1997. 
23. Daly JJ, Ruff RL. Feasibility of combining multi-channel functional neuromuscular stimulation with weight-supported treadmill training. J Neurol Sci 2004;225:105-15.

24. Daly JJ, Ruff RL. Electrically induced recovery of gait components for older patients with chronic stroke. Am J Phys Med Rehabil 2000;79:349-60.

25. Daly JJ, Barnicle K, Kobetic R, Marsolais EB. Electrically induced gait changes post stroke, using an FNS system with intramuscular electrodes and multiple channels. J Neuro Rehab 1993; 7:17-25.

26. Portney LG, Watkins MP. Foundations of clinical research: applications to practice. 2nd ed. Upper Saddle River: Prentice-Hall; 2000.

27. Faber MJ, Bosscher RJ, van Wieringen PC. Clinimetric properties of the performance-oriented mobility assessment. Phys Ther 2006; 86:944-54.

28. Behrman AL, Light KE, Miller GM. Sensitivity of the Tinetti Gait Assessment for detecting change in individuals with Parkinson's disease. Clin Rehabil 2002;16:399-405.

29. Tilson JK, Sullivan KJ, Cen SY, et al. Meaningful gait speed improvement during the first 60 days poststroke: minimal clinically important difference. Phys Ther 2010;90:196-208.

30. Duncan PW, for the LEAPS Investigative Team. Body-weightsupported treadmill rehabilitation after stroke. N Engl J Med 2011;364:2026-36.
31. Perry J, Garrett M, Gronley JK, Mulroy SJ. Classification of walking handicap in the stroke population. Stroke 1995;26: 982-9.

32. Tilson JK, Sullivan KJ, Cen SY, et al. Meaningful gait speed improvement during the first 60 days poststroke: minimal clinically important difference. Phys Ther 2010;90:196-208.

33. Ralston HJ. Energy-speed relation and optimal speed during level walking. Int Z Angew Physiol 1958;17:277-83.

34. Corcoran PJ, Brengelmann GL. Oxygen uptake in normal and handicapped subjects, in relation to speed of walking beside velocity-controlled cart. Arch Phys Med Rehabil 1970;51:7887.

35. Zarrugh MY, Todd FN, Ralston HJ. Optimization of energy expenditure during level walking. Eur J Appl Physiol Occup Physiol 1974;33:293-306.

36. Kim CM, Eng JJ. Magnitude and pattern of 3D kinematic and kinetic gait profiles in persons with stroke: relationship to walking speed. Gait Posture 2004;20:140-6.

37. Waters RL, Campbell J, Thomas L, Hugos L, Davis P. Energy costs of walking in lower-extremity plaster casts. J Bone Joint Surg Am 1982;64:896-9. 